\title{
Disruption of the mouse MRF4 gene identifies multiple waves of myogenesis
}

\section{in the myotome}

\author{
Ardem Patapoutian ${ }^{1, *}$, Jeong Kyo Yoon ${ }^{1, *}$, Jeffrey H. Miner ${ }^{1, \dagger}$, Shuling Wang ${ }^{1}$, Kevin Stark ${ }^{2}$ \\ and Barbara Wold ${ }^{1, \neq}$ \\ ${ }^{1}$ Division of Biology 156-29, California Institute of Technology, Pasadena, CA 91125, USA \\ ${ }^{2}$ Amgen Inc., 1840 DeHavilland Drive, Thousand Oaks, CA 91320, USA \\ *These authors contributed equally to this work \\ tPresent address: Department of Anatomy and Neurobiology, Washington University School of Medicine, St. Louis, MO 63110, USA \\ ¥Author for correspondence
}

\section{SUMMARY}

MRF4 (herculin/Myf-6) is one of the four member MyoD family of transcription factors identified by their ability to enforce skeletal muscle differentiation upon a wide variety of nonmuscle cell types. In this study the mouse germline MRF4 gene was disrupted by targeted recombination. Animals homozygous for the $M R F 4^{b h 1}$ allele, a deletion of the functionally essential bHLH domain, displayed defective axial myogenesis and rib pattern formation, and they died at birth. Differences in somitogenesis between homozygous $M R F 4^{b h 1}$ embryos and their wild-type littermates provided evidence for three distinct myogenic regulatory programs (My1-My3) in the somite, which correlate temporally and spatially with three waves of cellular recruitment to the expanding myotome. The first program (My1), marked initially by $M y f-5$ expression and followed by myogenin, began on schedule in the MRF4bh1/bh1 embryos at day 8 post coitum (E8). A second program (My2) was highly deficient in homozygous mutant MRF4 embryos, and normal expansion of the myotome failed. Moreover, expression of downstream muscle-specific genes, including $F G F-6$, which is a candidate regulator of inductive interactions, did not occur normally. The onset of $M y o D$ expression around E10.5 in wild-type embryos marks a third myotomal program (My3), the execution of which was somewhat delayed in MRF4 mutant embryos but ultimately led to extensive myogenesis in the trunk. By E15 it appeared to have largely compensated for the defective My2 program in MRF4 mutants. Homozygous $M R F 4^{b h 1}$ animals also showed improper rib pattern formation perhaps due to the absence of signals from cells expressing the My2 program. Finally, a later and relatively mild phenotype was detected in intercostal muscles of newborn animals.

Key words: MRF4/herculin/Myf-6, FGF-6, MHC embryonic, follistatin, myotome, rib, mouse

\section{INTRODUCTION}

In diverse developmental pathways, including skeletal myogenesis in vertebrates, specific sets of basic helix-loop-helix (bHLH) class transcription factors form regulatory networks important for cell fate specification and/or terminal differentiation (reviewed by Jan and Jan, 1993). In mammals, the MRF (muscle regulatory factor) group includes MyoD, myogenin, Myf-5 and MRF4/herculin/Myf-6, (reviewed by Weintraub, 1993) and together they compose the core of the myogenic bHLH net. Evidence from several lines of investigation have led to the view that these genes are individually and collectively important for muscle determination and differentiation. Both in tissue culture cells (reviewed by Olson, 1990) and transgenic animals (Hopwood and Gurdon, 1990; Miner et al., 1992), dominant gain of function assays have shown that each MRF can activate muscle-specific genes and, in permissive cell environments, drive wholesale conversion of the host cells to a myocyte-like phenotype. At the molecular level, MRFs are sequence-specific DNA binding proteins that bind to function- ally important sites in the enhancers of many muscle-specific genes (Murre et al., 1989; Weintraub et al., 1991). In vivo, MRF expression is largely restricted to skeletal muscle precursors and mature myofibers (Buckingham, 1992), consistent with functions specific to myogenesis. Finally, germline gene disruption experiments in the mouse are now providing stringent in vivo tests of inferences from prior expression and molecular studies. So far, these experiments have shown that $M y o D$ and $M y f-5$ are jointly important for formation and/or survival of muscle precursor populations (Rudnicki et al., 1993), while myogenin is needed for efficient and proper muscle differentiation in vivo (Hasty et al., 1993; Nabeshima et al., 1993). In addition to these myogenic phenotypes, null alleles of Myf-5 (Braun et al., 1992) and myogenin also affected axial skeletogenesis, disrupting to different degrees distal rib formation. Here, we describe disruption of the mouse MRF4 gene.

All known skeletal muscle in an adult vertebrate originates from cells of the dorsal prechordal and paraxial mesoderm (Wachtler and Christ, 1992). In the trunk and tail regions, this 
multipotential mesoderm is first segmented into somitic blocks in a rostrocaudal progression on both sides of the neural tube. Under the influence of signals from epidermis, neural tube and notochord, these somites subdivide into dermamyotome (muscle and skin precursors) and sclerotome (cartilage and bone precursors), and subsequently the dermamyotome further segregates into myotome and dermatome. Within the developing dermamyotome and myotome, there is a dynamic pattern of MRF expression such that each MRF is expressed in a distinctive spatiotemporal pattern that generally overlaps with expression of one or more other family members (reviewed, Buckingham, 1992; Smith et al., 1994). The pattern for MRF4 is different from the others in three major respects. First, its myotomal expression occurs in a discrete wave that begins at about day 9 post coitum (E9) and ends at around E11.5, while the others continue to be expressed significantly until at least E15 when the axial muscle masses derived from the myotome are quite well defined. Second, MRF4 is not involved in early myogenesis in the head or limb musculature but the other three MRFs are. Finally, MRF4 expression initiates a second wave at E16 and ultimately comes to dominate quantitatively over the other MRFs in adult muscle, an observation that led to the suggestion that MRF4 may be needed to maintain the differentiated skeletal phenotype (Miner and Wold, 1990).

In this work, disruption of the MRF4 gene produced both muscle and skeletal abnormalities in the mouse embryo and fetus. Molecular and cytological analysis of homozygous mutant $M R F 4^{b h 1}$ embryos showed that early and late waves of myogenic commitment and differentiation in the myotome occurred similarly in mutant and wild-type myotomes, but an intermediate myotomal expansion during the period of somitic MRF4 expression (approx. E9-11) failed. These observations, considered together with patterns of MRF expression and their respective mutant phenotypes, led us to propose a new model for myotome formation in which each of three myotomal MRF programs (My1-My3) drives a distinct wave of myotomal cellular expansion. In this model, different combinations of MRFs are required for execution of each wave of commitment and differentiation. The effects of the $M R F 4^{b h l}$ mutation on rib morphogenesis are contrasted with those of mutations in myogenin and Myf-5; myotomal cellular domains and specific signaling molecules produced from them are considered as candidates for intramyotomal and myotome/sclerotome interactions.

\section{MATERIALS AND METHODS}

\section{MRF4 inactivation in ES cells}

The linearized targeting plasmid was electroporated into CJ7 embryonic stem (ES) cells followed by selection in the presence of G418 and Gancyclovir. Selection of homologous recombination events over other integration sites was facilitated by the presence of two HSV$t k$ expression cassettes, one flanking each segment of MRF4 homology. 423 independent clones were isolated, and the clones containing a single, correct homologous recombination on MRF4 locus were identified by both Southern hybridization and PCR. From 23 positive clones, six were selected for injection into mouse blastocysts. Coat chimeras ranging from 5\% to greater than $90 \%$ were generated from six lines, of which two were transmitted to the germline. Heterozygous progeny were crossed with C57B6 mice. Most developmental timepoints assayed in this work were examined in both independent lines and no differences in phenotype were detected.

\section{Genotyping of progeny}

Genomic DNA was isolated from either yolk sac or tail biopsies. For Southern hybridization, $10 \mu \mathrm{g}$ of DNA was digested with either $B a m \mathrm{HI}$ and KpnI restriction enzymes, or BamHI and $S t u \mathrm{I}$ at $37^{\circ} \mathrm{C}$. DNA was fractionated on $0.8 \%$ agarose gel with Tris-Acetate-EDTA buffer, and then transferred to Hybond-N filter with $10 \times$ SSPE. Probe for hybridization was labeled with $\left[\alpha_{-}{ }^{32} \mathrm{P}\right] \mathrm{dCTP}$ using a randomprimed labeling kit (Boehringer Mannheim) according to the manufacturer's instruction. Hybridization was performed at $68^{\circ} \mathrm{C}$ overnight according to the method of Sambrook et al. (1989). For genomic PCR, $1 \mu \mathrm{g}$ of DNA was used in 29 cycles with the following three primers: MRF4-forward, GGGAGACTGATGCTCCATGACAGC (from MRF4 promoter); MRF4-reverse, GTGTTCCTCTCCACTGCTGTCGCT (from MRF4 exon 1); PGK-reverse, GCGCTACCGGTGGATGTGGAATG (from PGK promoter).

Table 1. Primers used in RT-PCR

\begin{tabular}{|c|c|c|c|}
\hline Gene & Forward primer & Reverse primer & Cycle no. \\
\hline MRF4 & CTACATTGAGCGTCTACAGGACC & CTGAAGACTGCTGGAGGCTG & 27 \\
\hline Myf-5 & TGAATGTAACAGCCCTGTCTGGTC & CGTGATAGATAAGTCTGGAGCTGG & 26 \\
\hline MyoD* & AGGCTCTGCTGCGCGACC & TGCAGTCGATCTCTCAAAGCACC & 26 \\
\hline FGF6 & GTGCTCTCTTCATTGCCATGAACAG & CCCCGTGAGCCTTCATCC & 28 \\
\hline MEF2D $\dagger$ & CAAGCTGTTCCAGTATGCCAG & AAGGGATGATGTCACCAGGG & 26 \\
\hline M-cadherin & CAGGTTCACCATCCTTGAAGGT & TGGGTCGTAGTCTTTGGAGTAGC & 26 \\
\hline ACHR- $\gamma$ & CAGCGCAATGGATTAGTGCAGG & GTCAGGCACTTGGTTGTAGTGGG & 27 \\
\hline$\alpha$ skeletal actin & TTATCGGTATGGAGTCTGCGGG & CACAGCACGATTGTCGATTGTGG & 22 \\
\hline MCK & TTCGGCAACACCCACAACAAGTTC & ACATAGTTGGGGTCCAGGTCGTC & 22 \\
\hline MHC-embryonic & GCAAAGACCCGTGACTTCACCTCTAG & GCATGTGGAAAAGTGATACGTGG & 23 \\
\hline MHC-perinatal & GAAGACCGCAAGAATGTGCTCC & СCTCCTGTGCTTTCCTTCAGCC & 22 \\
\hline PAX-1末 & CACATTCAGTCAGCAACATCCTG & TGTATACTCCCTGCTGGTTGGAA & 25 \\
\hline M-TWIST & AGCGGGTCATGGCTAACGTGCGGGA & GGAGCCGGTCCTTACCTAGG & 26 \\
\hline ID-1 & CTGGAGCTGAACTCGGAGTCTG & CTGAAAGGTGGAGAGGGTGAGG & 23 \\
\hline
\end{tabular}

*Hannon et al., 1992; †Martin et al., 1994; $\$$ Fan and Tessier-Lavigne, 1994; §Walterhouse et al., 1993. 


\section{RNA isolation and RT-PCR}

RNAs were prepared by the method of Chomczynski and Sacchi (1987) from the trunk (without limb) region of embryos from different developmental timepoints. Quantitative RT-PCR was carried out according to the method of Robinson and Simon (1991). Both reverse transcription and PCR were performed in the same tube in a single buffer with specific primers. AMV-RT (Promega) was used instead of MMLV-RT, and Taq antibody (Clontech) was also added to block Taq activity at lower temperatures. 22-28 cycles were used for different primer sets as shown in Table 1. An initial titration was carried out to assure that amplifications at high cycle numbers were still in linear range and quantitative (A. P. and B. W., unpublished data). All primer sets were designed to span at least one intron to distinguish RNA from DNA contamination, and the sizes of the products were between 200 and 500 bases. For the E18.5 samples, reverse transcription was carried out separately with random hexamer primers (Pharmacia).

\section{Whole-mount skeletal staining}

Newborn mice were skinned and eviscerated prior to fixation. Embryos were fixed directly in $100 \% \mathrm{EtOH}$. After fixation for 3 days, carcasses were incubated in acetone for 3 days. Bone and cartilage of mice or embryos were stained for 3 days at $37^{\circ} \mathrm{C}$ with a solution containing $0.005 \%$ alizirin red $\mathrm{S}, 0.015 \%$ alcian blue $8 \mathrm{GX}, 5 \%$ acetic acid and $70 \%$ ethanol. The samples were incubated in a $20 \%$ glycerol $/ 1 \%$ $\mathrm{KOH}$ solution for 6 hours at $37^{\circ} \mathrm{C}$ and then kept at room temperature until the skeleton was clearly visible through the surrounding tissue.

\section{Frozen sections and antibody staining}

Embryos were fixed in $4 \%$ paraformaldehyde at $4{ }^{\circ} \mathrm{C}$ overnight. Embryos younger than E11 were sunk into $15 \%$ sucrose and $7.5 \%$ gelatin in PBS solution and then frozen in OCT (Tissue-Tek). Older embryos were immediately frozen in OCT. Sections of 10-20 $\mu \mathrm{m}$ thickness were obtained using a cryostat, and were blocked for 20 minutes in $10 \%$ goat serum and 3\% BSA in PBS before applying the primary antibody for 1-3 hours at room temperature. The secondary antibody solution was applied for 1 hour. Antibodies against myosin heavy chain, (MF20; 1:10 dilution; mouse IgG2b; Developmental Studies Hybridoma Bank), striated muscle-specific $\alpha$ actinin (1:400 dilution; mouse IgG1; Sigma), myogenin (F5D; 1:5 dilution; mouse IgG1; courtesy of W. Wright), and MyoD (1:10 dilution; mouse IgG1; Novocastra Lab. Ltd.) were used. Secondary antibodies were conjugated to fluorescein and specific to mouse IgG isotypes and used as 1:100 dilution in 3\% BSA in PBS (Southern Biotechnology Associates). Images were captured digitally using a confocal microscope (BioRad).

\section{Histology}

Newborn mice were fixed with $4 \%$ paraformaldehyde, dehydrated gradually with ethanol, and embedded in paraffin. $16 \mu \mathrm{m}$ sections were stained with both hematoxylin and eosin. Embryos were frozen in OCT after fixation with $4 \%$ paraformaldehyde, sectioned at $20 \mu \mathrm{m}$ thickness, and stained with both hematoxylin and eosin.

\section{RESULTS}

\section{Construction of MRF4 ${ }^{\text {bh }}$ mutant mouse strains}

Two independent strains of mice were generated in which the functionally essential bHLH domain of the MRF4 gene was deleted from the chromosome via targeted homologous recombination in embryonic stem cells and subsequent transmission into the mouse germline. The targeting plasmid was designed to create a null allele of MRF4 by replacing codons 40-173 of MRF4 (Miner and Wold, 1990) with a $p g k$-neo selection cassette (Fig. 1A). This eliminates the entire basic-helix-loophelix domain which is required for MRF protein dimerization and DNA binding in biochemical assays (Lassar et al., 1989, 1991) and is also required for myogenic activity in transfection assays (Tapscott et al., 1988; Yutzey et al., 1990). We call this the MRF4 $4^{b h l}$ allele. Blastocyst injections produced chimeras from six different targeted embryonic stem cell lines; two independent cell lines from different electroporation experiments were ultimately established in the germ line. Heterozygous males and females appeared grossly normal and were fertile. Genotypes of progeny were determined by Southern hybridization and by PCR of DNA from tail or yolk sac. Southern blot analysis showed that the map of the targeted locus is as predicted if homologous recombination occurred between the vector and the host chromosome, as indicated (Fig. 1B). Additional Southern blot analysis showed the related downstream Myf-5 locus to be intact and unaffected (data not shown). Progeny from crosses of $M R F 4^{b h l}$ heterozygotes harvested during gestation yielded 47 (29\%) wild-type, 85 (53\%) heterozygous and $28(18 \%)$ homozygous embryos, results that are within $95 \%$ confidence limits for 1:2:1 Mendelian ratios. Homozygous animals died shortly after birth with $100 \%$ penetrance. They showed respiratory distress which may be the main cause of death.

\section{MRF4 is an important regulator of early somitogenesis}

Quantitative RT-PCR and immunocytological assays were used to compare littermates of wild-type, heterozygous, and homozygous genotypes. The earliest marker of myotomal commitment presently known is $M y f-5$. Previous in situ hybridizations have shown that $M y f-5$ expression in somites is first detectable at E8, when the first four somites have just formed (Buckingham, 1992). The RT-PCR analysis performed here also showed no expression of $M y f-5$ in wild-type E7.5 embryos, but by E8 (6-7 somites) wild-type (data not shown), heterozygous, and homozygous $M R F 4^{b h l}$ embryos all showed comparable levels of $M y f-5$ expression (Fig. 2A). As expected, the other MRFs were not yet expressed at this time in heterozygous or homozygous embryos. Proper $M y f-5$ initiation would suggest that the MRF4 knockout allele we have constructed does not exert detectable cis-effects on the Myf-5 gene which is located $7 \mathrm{~kb}$ downstream (Miner and Wold, 1990). By E9 (13-14 somites) myogenin protein expression (Fig. 2B) was detected, by immunostaining, in heterozygous and homozygous $M R F^{4 b h 1}$ embryos. We conclude that the earliest myotome formation is largely unaffected by this $M R F 4$ mutation, and this is consistent with the fact that MRF4 is not expressed detectably until after E9 (Bober et al., 1991; Hinterberger et al., 1991; Smith et al., 1994).

The earliest mutant phenotype detected in $M R F^{4 b h 1}$ animals was a deficit in myotome development that corresponded in time with the first wave of MRF4 expression, beginning around E9 and ending around E11. Quantitative RT-PCR was used to measure expression of an expanded set of genes normally expressed in somites at this time. For all studies at E10 and later, trunk regions were dissected and analyzed without head and limbs. The intent was to eliminate interference from MRF4-independent myogenic programs that are active in head and limb. By E10, expression of Myf-5, myogenin, and MyoD in the trunk were significantly reduced relative to their levels 

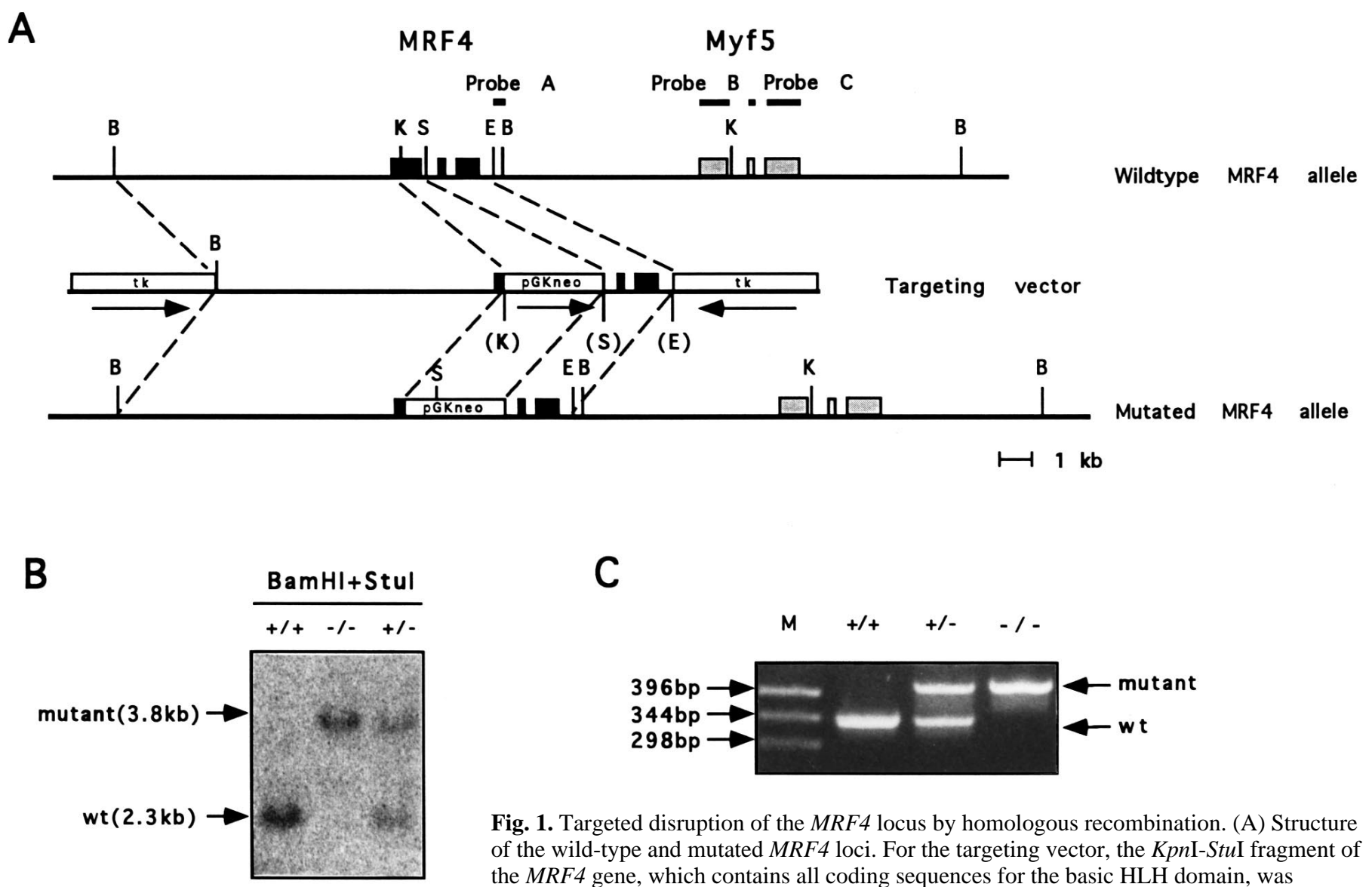

Fig. 1. Targeted disruption of the MRF4 locus by homologous recombination. (A) Structure of the wild-type and mutated MRF4 loci. For the targeting vector, the KpnI-StuI fragment of the MRF4 gene, which contains all coding sequences for the basic HLH domain, was replaced with a $p g k$-neo cassette for positive selection in G418. HSV-tk cassettes flanked the targeting vector's homologous sequences to maximize the efficiency of negative selection with gancyclovir. Direction of arrows in the targeting vector represents the direction of transcription units. Exons of MRF4 and Myf-5 genes are shown as black and gray rectangles, respectively. The transcriptional direction of both MRF4 and Myf-5 genes is from left to right. Abbreviations for restriction enzymes are B, BamHI; E, EcoRI; K, KpnI; and S, StuI. Restriction enzyme sites in parentheses were lost in the cloning process. (B) Southern hybridization of genomic DNA. Genomic DNA isolated from tail was digested with BamHI and StuI, fractionated on a 0.8\% agarose gel, and transferred to Hybond-N. Using probe A (see A), $2.3 \mathrm{~kb}$ and $3.8 \mathrm{~kb}$ bands that represent wild-type and mutated MRF4 alleles, respectively, were detected. (C) Genomic DNA PCR. DNA was amplified with locus-specific primers (see Materials and methods) for 29 cycles and analyzed on an agarose gel. A $1 \mathrm{~kb}$ ladder was used as a marker (M).

A

\section{GAPDH}

Myf-5

myogenin*

MRF4* e8
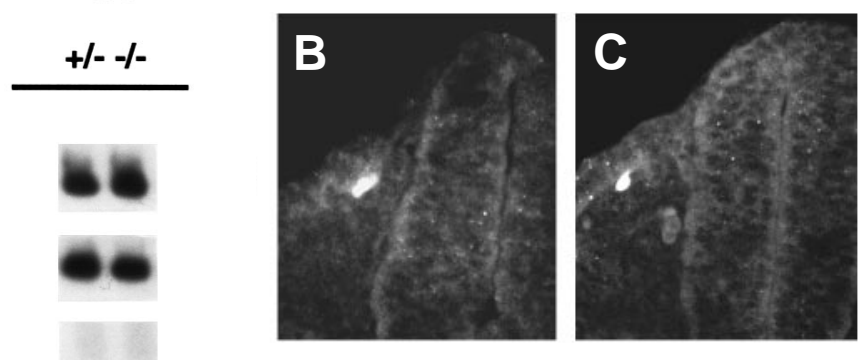

expression (*) (B,C) Transverse sections of heterozygous (B) and homozygous (C) E9 (13 somite) embryos showing myogenin protein expression in caudal (young) somites.

in wild-type littermates (Fig. 3). When normalized to GAPDH levels, quantitation of band intensities showed that $M y f-5$, myogenin, and MyoD RNA levels in homozygotes were $25 \%$, $8 \%$, and $10 \%$ of wild-type levels, respectively. Interestingly, $M R F 4, M y f-5$, and MyoD levels were reproducibly reduced in the heterozygotes, suggesting that haploinsufficiency in $M R F 4$ is not compensated by upregulation of other family members and, moreover, that haploinsuffiency in MRF4 radiates through the MRF network to include other members. Among downstream muscle-specific differentiation genes surveyed, 


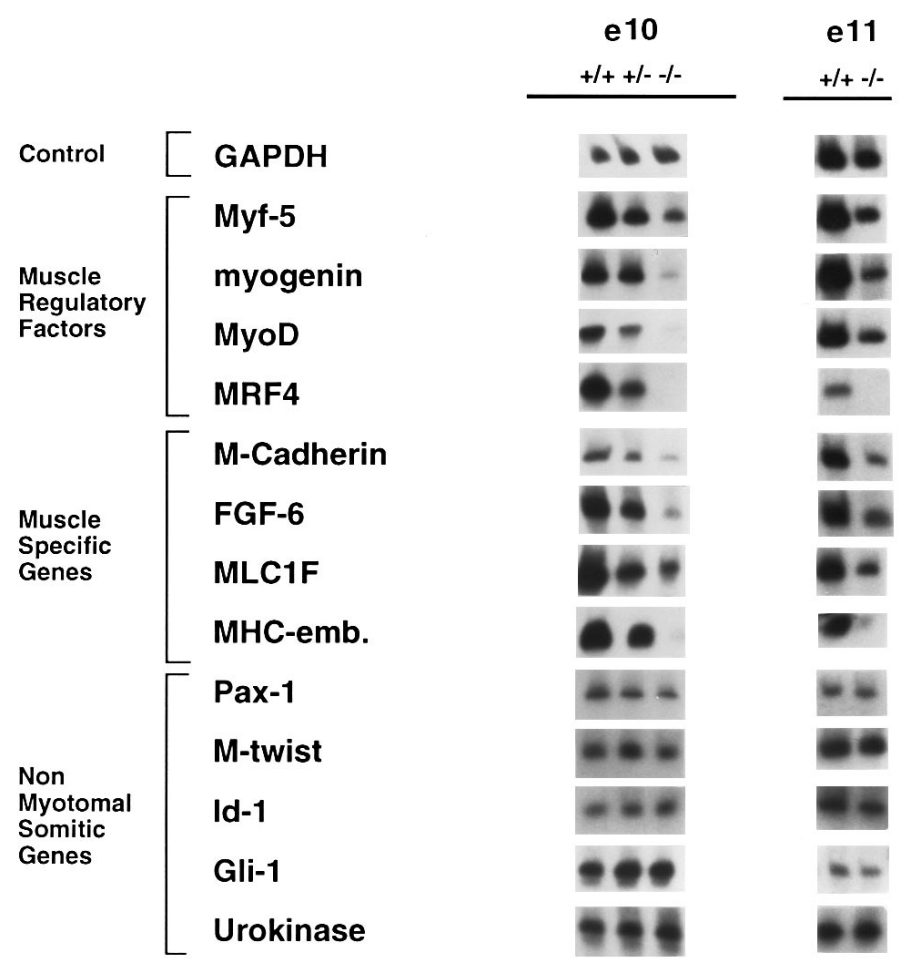

Fig. 3. Early $M R F 4$ expression is required for muscle-specific gene expression in myotomes. Quantitative RT-PCR on MRF4 ${ }^{b h 1}$ homozygous and control littermates from E10 and E11 trunk (without head and limb) embryos with muscle-specific and other non myotomal somitic genes. At E10 all muscle-specific genes examined are expressed at lower levels in homozygous animals. Heterozygous animals also show some downregulation compared to wild-type littermates. Non-myotomal somitic genes and control GAPDH are expressed at normal levels in MRF4 knockouts. At E11, musclespecific genes are still expressed at reduced levels in MRF4 knockouts, however, the downregulation of some genes, such as $M y o D$, is less dramatic compared to that seen at E10.

MRF4 ${ }^{\text {bhl }}$ homozygotes showed very substantial deficits, although different genes were affected to different extents. For example, FGF-6 and M-Cadherin, genes that are interesting for their potential effects on cell-cell interactions, were expressed at markedly reduced but still detectable levels ( 8 and $25 \%$ of wild type, respectively). However, the effect on the embryonic myosin heavy chain $(M H C-e m b)$ was more dramatic, as its RNA appears to be entirely absent from mutant embryos at E10, even though in wild-type embryos it has accumulated at high levels. Since defects in rib morphogenesis become evident later in development and might arise from earlier sclerotomal defects, an array of sclerotomal markers including Pax-1, M-Twist, Id-1, Gli-1, and Urokinase were also surveyed. No noticeable effects were detected in any of the sclerotomal markers tested (Fig. 3).

In wild-type animals, MyoD expression begins gradually at E9.5 (Smith et al., 1994), and it accumulates to significant levels by E11 (Sassoon et al., 1989). This is an informative time to evaluate the impact of $M R F 4^{b h}$, because MRF4 is concurrently disappearing from wild-type myotomes. At E11, MRF members were still expressed at reduced levels in $M R F 4^{b h 1 / b h l}$ embryos compared to wild type. However, the reduction was less dramatic than that observed one day earlier. Quantitation of band intensities normalized to $G A P D H$ showed Myf-5, myogenin, and MyoD RNA levels in homozygotes were $25 \%, 21 \%$, and $32 \%$ of wild-type levels, respectively. The picture was similar for muscle-specific differentiation markers. We conclude that the severe deficit in myotomal myogenesis observed at E10 is moderated by E11, and this was observed in both knockout lines (Fig. 3 and data not shown).

An important issue is how the gene expression observed in whole trunk RNA specimens is distributed among cells of the developing somite. At one extreme, RNA measurements in Fig. 3 could reflect differences in levels of gene expression distributed over identical cellular domains in the mutant and wild type; at the other extreme, all RNA could be accounted for by changes in the number and/or type of myotomal cells in mutant versus wild type. To help discriminate between these possibilities, E11 wild-type and homozygous $M R F 4^{b h l}$ littermates were sectioned and probed with antibodies to relevant musclespecific regulators and structural proteins, including myogenin, MyoD, $\alpha$-actinin (Fig. 4), and myosin heavy chain (data not shown). The myotomes of mutant animals were greatly reduced in size and cell number. Differentiated myocytes could be identified by their expression of $\alpha$-actinin (Fig. 4A,B,G,H). In the homozygotes, these myocytes were confined mainly to the dorsal myotomal domain. This was most obvious in caudal hindlimb level somites which developmentally lag behind the more mature rostral forelimb somites. By E11, MyoD expression in wild type and in mutants has begun to accumulate (Fig. 4E,F,K,L). At the cellular level, MyoD protein expression outlines a new and much larger presumptive myotomal domain in the mutants than that shown with myogenin or $\alpha$-actinin, and the MyoD domain was concentrated more ventrolaterally.

\section{Axial myogenesis in MRF4 $4^{\text {bh } 1}$ homozygotes is grossly normal by $\mathrm{E} 14$}

By E14, no MRF4 expression in wild-type embryos can be detected, and it does not reappear until about E16. However, the period of myotomal myogenesis coincident with the expression of $M y o D$, which begins around E10.5, has been active for several days, and during this time axial muscle mass has expanded significantly. At E14 the RT-PCR analysis was again focused on axial musculature. Comparable expression levels were found for most muscle regulators and structural genes tested in wild-type, heterozygous and homozygous $M R F 4^{b h l}$ fetuses from both knockout strains (Fig. 5 and data not shown). Exceptions were $M y f-5$ and $M$-Cadherin, both expressed at reproducibly reduced levels in mutant animals. At the cellular level, we observed grossly normal muscle mass patterns by histological staining of E15 embryos (Fig. 6A,B) and by muscle-specific antibody staining of both limb muscles and intercostal muscles (data not shown).

\section{MRF4 has subtle effects on intercostal muscles in the newborn}

To examine the effects of the second wave of MRF4 expression, which starts around E16 and correlates with the timing of widespread secondary differentiation of muscle, we examined RNA from the ribcage region of E18.5 and newborn animals by RT-PCR. MRF $4^{b h 1 / b h l}$ animals expressed largely normal levels of most muscle-specific markers, although a 


\section{Forelimb level somites}

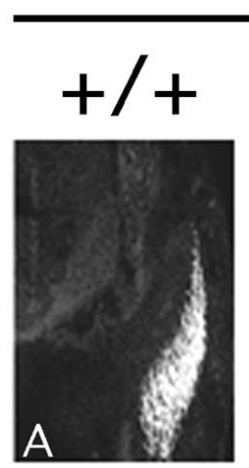

$\alpha$-actinin

\section{myogenin}
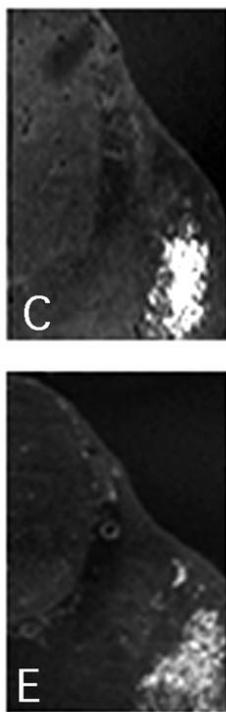
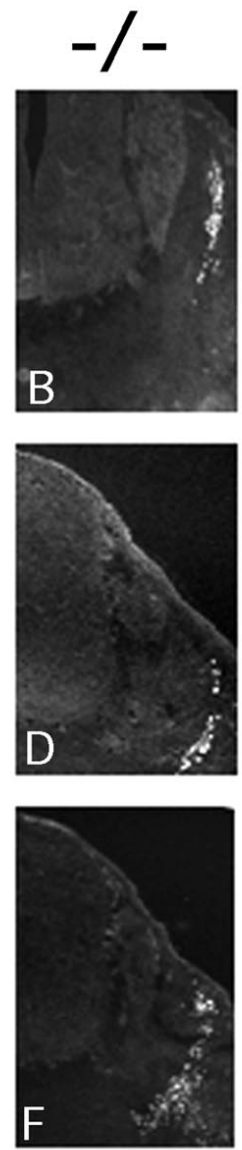

Hindlimb level somites
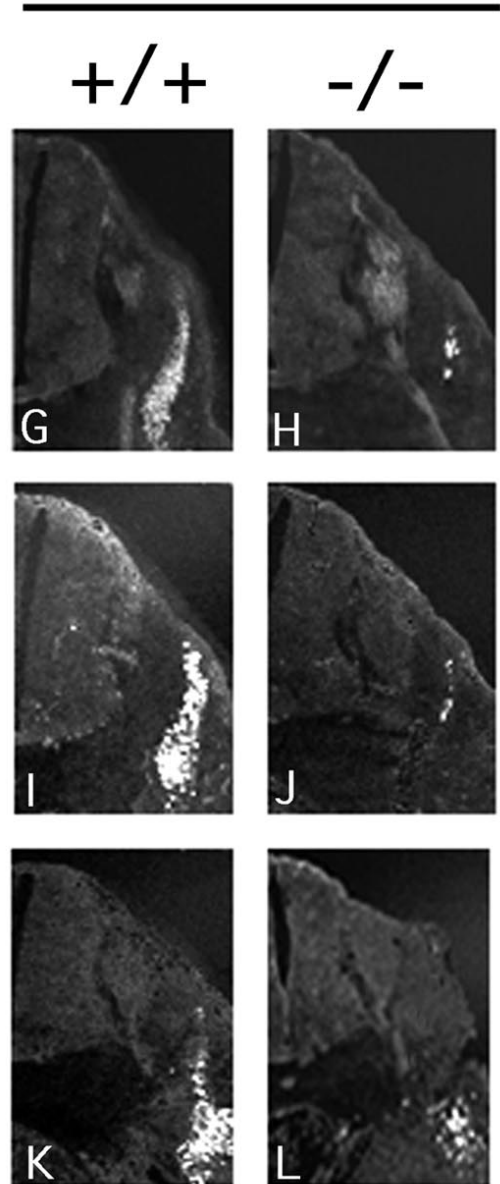

Fig. 4. Effects of MRF4

knockout on myotomal domains at E11.

Transverse sections of wild-type and MRF4 ${ }^{b h 1}$ homozygous E11

littermates stained with antibodies against $\alpha$ actinin (A, B, G, H), myogenin $(\mathrm{C}, \mathrm{D}, \mathrm{I}, \mathrm{J})$, and $\operatorname{MyoD}(\mathrm{E}, \mathrm{F}, \mathrm{K}, \mathrm{L})$. All panels show dorsal region of transverse sections. The ventral side of embryo is facing downwards, and the neural tube is on the upper left hand corner. Forelimb-level somites (A-F) represent more mature myotomes than do hindlimb level somites (G-L). The number of cells expressing musclespecific markers is strongly reduced in homozygous animals. $\alpha$ actinin expression in both forelimb $(\mathrm{A}, \mathrm{B})$ and hindlimb $(\mathrm{G}, \mathrm{H})$ level myotomes is reduced to the dorsal, earlier forming myogenic cells in MRF4 knockouts. Myogenin expression in the younger hindlimb

level somites (I,J) is restricted to a few cells of the dorsal myotome in the MRF4bhl/bhl animals. In the forelimb region (C,D), myogenin expression in the MRF4 knockout starts expanding ventrally; however, it is still in a very restricted region compared to the wild-type littermate. MyoD expression (E,F,K,L) is the least affected in homozygous animals. Although fewer cells express MyoD in the myotomal region of $M R F 4^{b h l / b h l}$ animals, the domains of expression are comparable in wild-type and homozygous animals at both limb levels.

modest reduction in Myf-5 and some muscle-specific structural genes was observed (Fig. 5). Similar results were obtained for RNA isolated from limbs (data not shown). However, examination of sections from E18.5 and newborn mice revealed that some intercostal muscles associated with ribs 3-5 were either disorganized or significantly reduced in fiber number in MRF4 $4^{\text {bhl/bhl }}$ animals. This pheontype varied in intensity among different homozygous animals, and it remains to be determined whether genetic background is playing a significant role. In animals displaying the most intense intercostal abnormalities, substantial numbers of mononuclear cells were present in homozygous animals (Fig. 6C,D). Antibody staining for myosin heavy chain (data not shown) and $\alpha$ actinin showed that these cells were not differentiated myocytes (Fig. 6E,F). This effect on myogenesis was not evident prior to the period of fetal MRF4 expression (Fig. 6A,B).

\section{Rib defects in MRF4 null mutant mice}

Homozygous mice showed obvious respiratory distress and died shortly after birth. Rib defects have been observed previously in Myf-5- and myogenin-null mutant mice (Braun et al., 1992; Hasty et al., 1993; Nabeshima et al., 1993). We therefore examined whether MRF4-null mutant mice exhibit skeletal abnormalities, by staining with alizirin red $\mathrm{S}$ and alcian blue to detect bone and cartilage, respectively. In newborn mice homozygous for $M R F 4^{b h 1}$, rib development is severely disturbed (Fig. 7). The abnormalities include rib bifurcation, fusion of rib cartilage from adjacent ribs, truncated ribs that fail to attach to the sternum, and disorganized ossification in the sternum. Rib foreshortening in ribs 2-12 was usually less than $20 \%$ of total length, and this led to variable failure to join the sternum. Interestingly, the first and last (13th) ribs were more dramatically shortened compared with the others. Some ribs also displayed abnormal angles of extension (Fig. 7G,I). Finally, the tuberculum anterior that is normally present on the 6th cervical vertebrae was absent in most MRF4 ${ }^{b h 1 / b h l}$ mice ( $83 \%$ penetrance). Other skeletal elements, including proximal regions of ribs and vertebrae appeared to be normal (data not shown).

To examine when rib defects develop relative to chondrogenesis and ossification, E14 embryos were stained with both alizirin red $\mathrm{S}$ and alcian blue. Normally, rib cartilage cytodifferentiation in mice begins at E13, and ossification begins at E14 (Rugh, 1968). In all genotypes, the skeleton at E14 was 


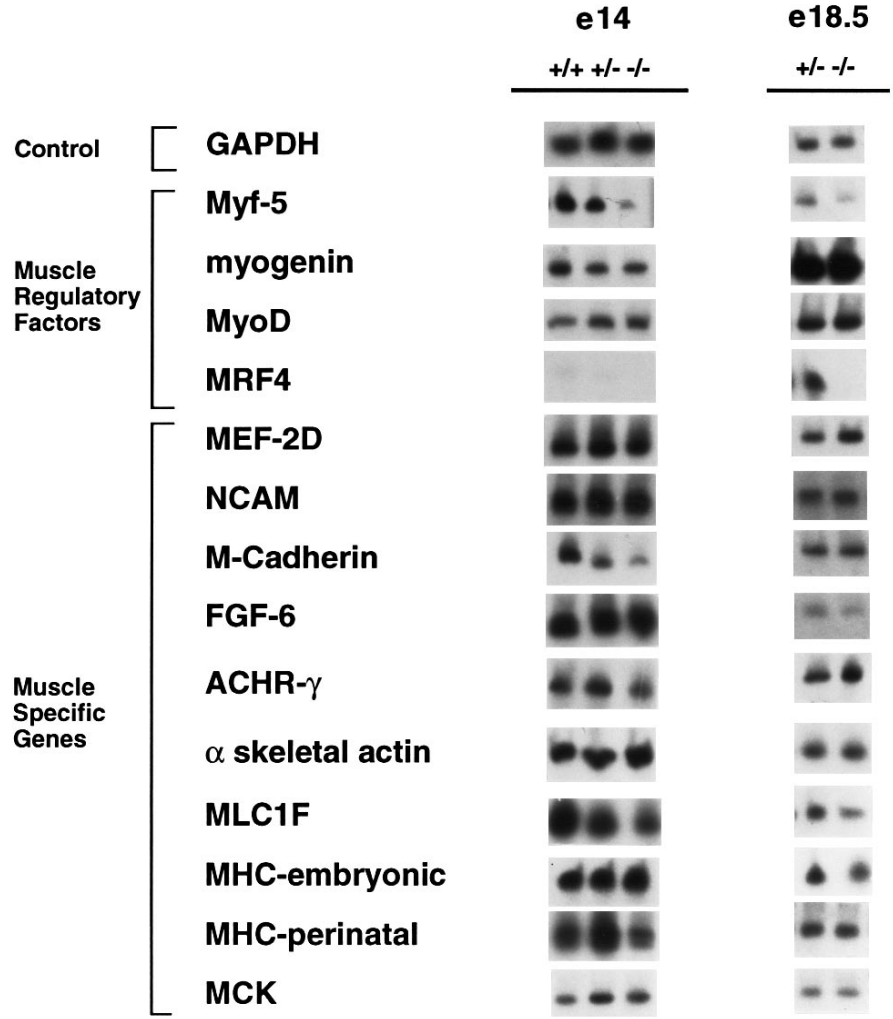

Fig. 5. Expression of muscle-specific genes in mice lacking $M R F 4$ during late embryogenesis. Quantitative RT-PCR on MRF4 knockout and control littermates from E14 and E18.5 embryos. RNA was isolated from the ribcage region of animals, avoiding internal organs such as heart. At both timepoints, most muscle-specific genes and control GAPDH show normal levels of expression in homozygous animals. Myf-5 levels are lower in MRF4 ${ }^{b h 1 / b h l}$ mice, and no MRF4 expression is observed. $M$-Cadherin is downregulated in homozygous animals at E14, while $M L C 1 F$ and $M H C$-embryonic are slightly downregulated at E18.5.

entirely cartilaginous except for the clavicle and the earliest ossification centers of facial bones. However, in homozygous $M R F 4^{b h 1}$ mutants, the rib bifurcations and truncated rib forms were already clearly visible (Fig. 7J,K). Thus, cytodifferentiation of most rib cartilage occurred at the normal time by this measure, and major rib pattern formation defects were clearly visible as soon as chondrogenesis rendered rib anlagen histochemically visible. These events occur well before the second period of MRF4 expression that begins at E16.

\section{DISCUSSION}

In this study the mouse MRF4 (herculin/Myf-6) gene was disrupted by targeted recombination. Animals homozygous for this $M R F 4^{b h 1}$ allele, which deletes the bHLH domain, displayed phenotypic effects on axial myogenesis and on rib pattern formation. They ultimately died at birth of apparent respiratory insufficiency. A substantial failure in myotomal development of homozygous mutants was observed, and it corresponded with the early somitic wave of MRF4 expression (E9-11). At the molecular level this generated a gross but transient deficiency in expression of other MRFs and some muscle-specific differentiation genes, including $F G F-6$ and $M$ Cadherin, which may be important in pattern formation and inductive interactions with the sclerotome (see below). The early myotomal deficit was largely overcome by subsequent myotomal expansion after the end of the MRF4 expression period in the myotome. However, perhaps as a consequence of the earlier myotomal phenotype, rib pattern formation was disrupted, and may be the primary cause of lethality. A late fetal muscle phenotype was also detected in some intercostal muscles of newborn mice, suggesting a possible effect from the lack of MRF4 expression that normally begins in muscles at E16; this might also contribute to lethality in the mutants.

\section{$M R F^{4 b h 1}$ reveals three waves of myotomal expansion, each dependent on a different set of MRFs}

A striking aspect of myotome formation in $M R F 4^{b h}$ homozygotes was the observation that an entire cellular myotomal domain appeared to be missing. Comparison of mutant and wild-type embryos before, during and after the window of MRF4 somitic expression leads us to propose the model shown in Fig. 8 for myotome biogenesis in the mouse. It identifies three different myotomal MRF programs (My1, My2 and My3) with three waves of myotomal cellular commitment and differentiation that result in production, at the cellular level, of primary, secondary, and tertiary myotomes. This nomenclature refers to different spatiotemporal phases of myotome formation, and should not be confused with primary and secondary myocytes that refer to embryonic and fetal myogenic differentiation, respectively. The My1 program is first and begins at E8; it uses Myf-5 and myogenin. By E9, this program has produced differentiated myocytes that are expressing myogenin and structural markers such as cardiac and skeletal $\alpha$ actin (Buckingham, 1992) in a small domain that typically includes less than 20 cells per somite at the future forelimb level. These cells are concentrated dorsally in the somite. The expression of Myf-5 protein in a domain of this size and position was recently described in a detailed study by Smith and Miller (Smith et al., 1994). Previous studies of a Myf-5 gene disruption (Myf-5 $5^{m l}$; Braun et al., 1992, 1994) have shown that there is no detectable myocyte differentiation in Myf-5 deficient homozygotes until E10.5. This suggests that $M y f-5$ function is essential for the My1 program, and is consistent with expression patterns. Whether myogenin is also essential for execution of this MRF program is not certain, as phenotypic data is not yet available for myogenin null mutants at the early times (Hasty et al., 1993; Nabeshima et al., 1993). The My1 program is initiated on schedule by both molecular and cellular assays, in the MRF4 ${ }^{b h 1}$ homozygotes (Fig. 2).

The phenotype of $M R F 4^{b h l}$ homozygotes suggests the existence of a second MRF program (My2) that is needed to execute a new wave of myogenic recruitment in the myotome. This myotomal expansion normally occurs during the period of MRF4 expression beginning at about E9 in rostral somites, and involves an increase of at least 15 -fold in the number of cells expressing myogenin or other skeletal muscle markers (Smith et al., 1994). The most straightforward interpretation of data from our MRF4 gene disruption is that the proposed secondary wave of myotomal expansion requires MRF4 function. Myf-5 is also required, because $M y f-5^{m l}$ homozy- 


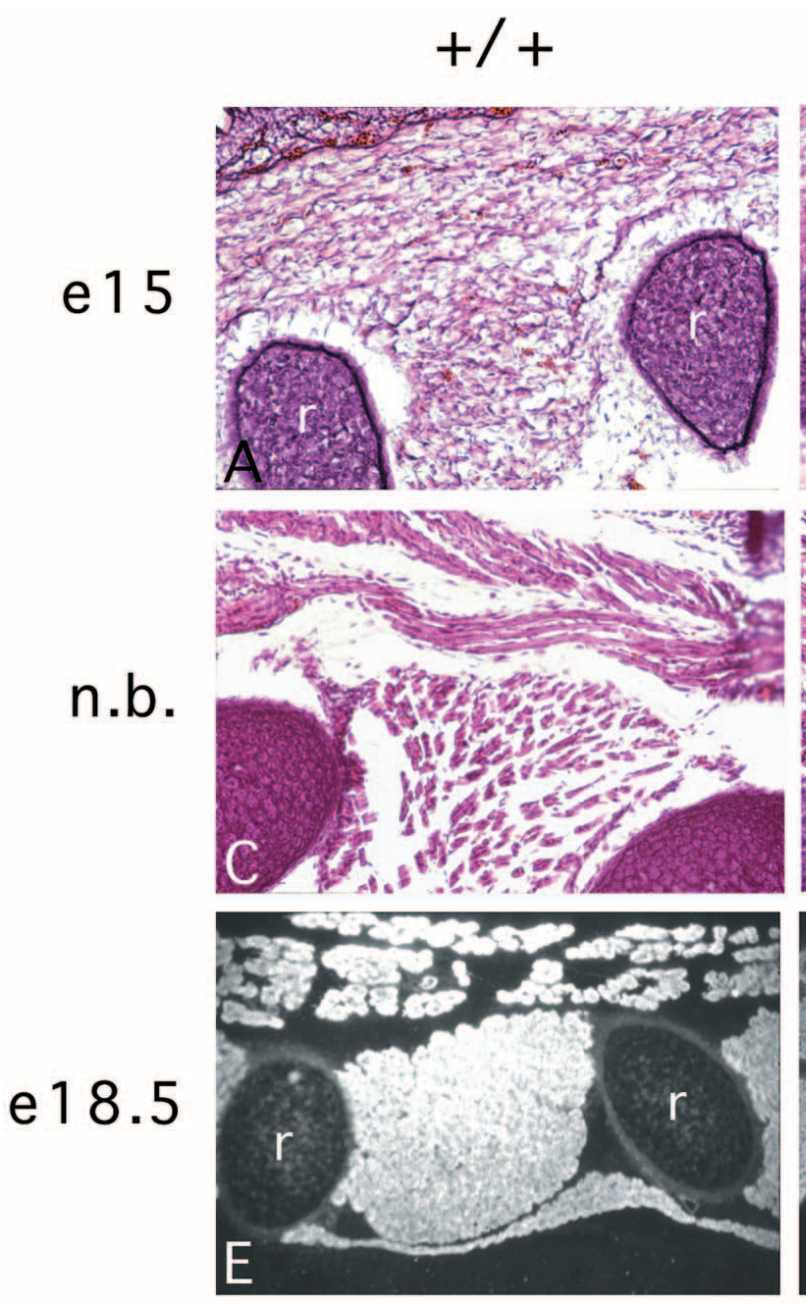

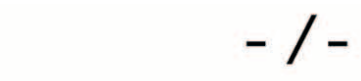
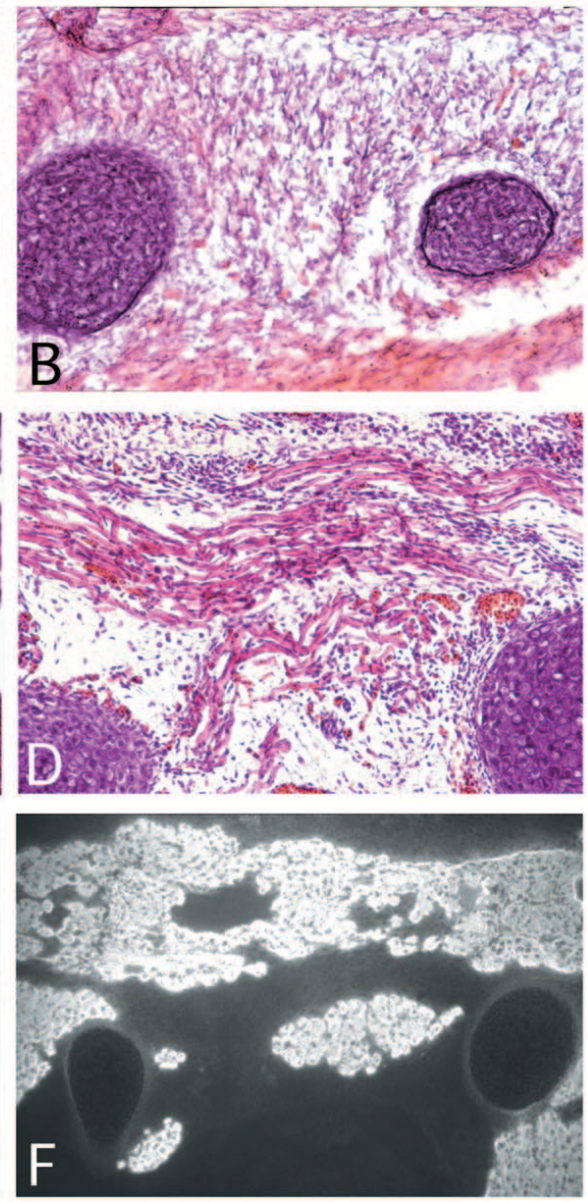

Fig. 6. Abnormal intercostal muscle formation at E18.5 and newborn in MRF4 $4^{b h 1 / b h l}$ mice. Frozen sections of E15.0 day embryos $(A, B)$ or sections of paraffin embedded newborn mice $(C, D)$ were stained with hematoxylin/eosin. Unlike the wild-type mice (C), disorganized muscle fibers and an increased number of mononuclear cells are seen in intercostal muscle of newborn MRF4 $4^{b h 1 / b h l}$ mice (D). However, intercostal muscle looks similar in both wild-type (A) and $M R F 4^{b h 1 / b h 1}$ (B) embryos at E15. Immunostaining of intercostal muscles with $\alpha$ actinin antibody shows $M R F 4^{b h 1 / b h l}$ mice (F) have abnormal muscle formation between ribs compared to wild-type littermate (E) at E18.5 (r, rib). gotes form neither the proposed primary or secondary myotomes, nor do they turn on MRF4 or other muscle-specific genes during this time (Braun et al., 1994). It is not clear, however, whether the dependence of secondary myotome formation on Myf-5 is cell autonomous or not. Thus in one scenario, Myf-5 expressing myoblasts within the primary myotome would migrate, change their MRF expression pattern (including initiation of MRF4 expression) and then form the secondary myotome. In a nonautonomous mechanism, mesodermal precursor cells neighboring the primary myotome could be directly induced to express MRF4 and myogenin and thus commence formation of the secondary myotome. In either case, $M y o D$ is not widely expressed until later times, and does not significantly compensate. It is interesting that myogenin null embryos apparently show normal somitic and myotomal morphology during the My2 program, and it will now be useful to examine muscle-specific gene expression between E8.5 and E10.5 in myogenin knockout mice to see whether the secondary wave of muscle differentiation proposed here occurs normally.

The proposed My3 program is marked by the onset of MyoD expression, and prominent myogenin expression. Together, they appear sufficient to direct a third major cellular expansion that produces the tertiary myotome of Fig. 8 between E11.5 and 15. Thus, in $M y f-5^{m 1}$ null embryos, there is no detectable myotome formation until the onset of MyoD expression around
E10.5, but that following onset of its expression a large myotome quickly forms, and subsequent axial myogenesis appears surprisingly normal (Braun et al., 1994). This led those investigators to propose the regulatory and functional independence of a MyoD driven myotome, and data presented here lead us to identify it as the third of three waves of myogenesis in the mouse myotome. MRF4 is not detectably expressed during most of the My3 period, nor is there any evidence that it can be accessed to compensate for MyoD when $M y o D$ has been mutated (Rudnicki et al., 1992). However, in the $M R F 4^{b h 1}$ homozygotes, the timing of the MyoD dependent myotome expansion was somewhat delayed, suggesting the possibility of positive inductive interaction between My2 and My3. Myf-5 expression normally declines between E11 and 16, and its domain of expression does not appear to fully overlap the expanded area in which MyoD and myogenin are prominent (Smith et al., 1994). However, in $M y o D$ knockout mice, Myf5 appears to compensate (Rudnicki et al., 1992); it is expressed at relatively elevated levels in these animals for an extended period and they ultimately appear to have normal axial musculature. This is one of several situations in which it is unclear whether compensation is at the level of cells or at the level of MRF molecules. Thus, compensation might represent the expansion of a pool of cells that express Myf-5 and myogenin or might instead reflect crosstalk among MyoD family regulators within a cell. 

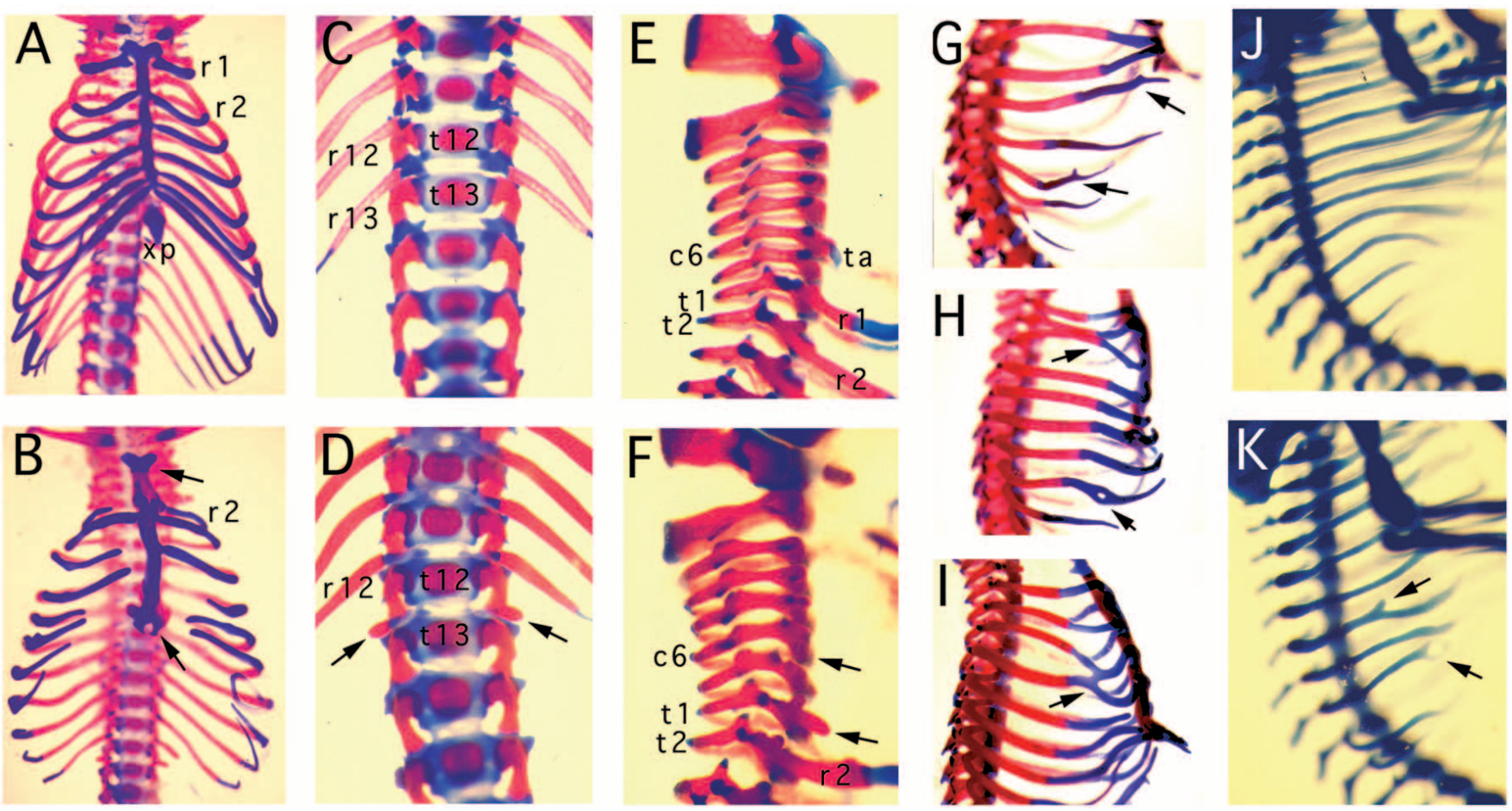

Fig. 7. Skeletal defects in $M R F 4^{b h l / b h l}$ mice. Skeletons of wild type and $M R F 4^{b h l / b h l}$ mice were stained with alizirin red $\mathrm{S}$ and alcian blue. (A,B) Ventral view of thoracic region of wild-type (A) and $M R F 4^{b h 1 / b h l}$ (B) newborn mice. While the first seven ribs are attached to the sternum in wild-type mice, only a few ribs are connected in $M R F 4^{b h l / b h l}$ mice. Anomaly of xiphoid process and severe truncation of first rib is also seen in $M R F 4^{b h l} / b h l$ mice (arrows). (C,D) Ventral view of lower thoracic vertebrae of newborn mice. Unlike wild type (C), the 13th rib appears as an anlage in $M R F 4^{b h 1 / b h 1}$ (D, arrow). (E,F) Lateral view of cervical vertebrae of newborn mice. In $M R F 4^{b h 1 / b h 1}$ (F), the tuberculum anterior on the 6th cervical vertebra is missing, and a very truncated first rib is observed (arrows). (G-I) Lateral view of thoracic region of newborn MRF4 ${ }^{b h l / b h l}$ mice. MRF $4^{b h l / b h l}$ skeletons show a bifurcation, a fusion, and abnormal angle of rib extension (arrows). (J,K) Lateral view of thoracic region of E14 embryo. Rib defect is already obvious at E14 in the MRF4 ${ }^{b h 1 / b h 1}$ embryo (K, arrows). Abbreviations: xp, xiphoid process; $r$, rib; t, thoracic vertebrae; c, cervical vertebrae.

\section{Rib pattern formation phenotypes in MRF4 ${ }^{b h 1 / b h 1}$ mice}

The rib morphogenesis phenotypes in the $M R F 4^{b h 1}$ homozygotes are quite different from those of the $M y f-5^{m l}$ homozygotes and are more similar to the myogenin null rib defects. The Myf-5 mutant has only rudimentary rib stumps at all vertebrae, but the $M R F 4^{b h l}$ homozygotes have extensive rib formation that is mainly disrupted at distal locations close to the sternum. This suggests that the basis for the pattern formation disturbances in these animals are mainly interactions between myotome and sclerotome that depend on cells and signals produced in the My2 myotome of the model, while the more dramatic reduction in rib formation found in the $M y f-5$ mutant might be attributable to failure of the My1 program. Christ and colleagues (Huang et al., 1994) have recently reported that in the chick-quail system, cells from the somitocoele of early epithelial somites are rib progenitors. Moreover, homotypic somitic transplantation experiments revealed that rib progenitors from one somite can later be found in two ribs; the transplanted somite and the next most rostral rib. At slightly later developmental times, cytological studies have noted the close apposition of lateral sclerotomal cells to the emerging myotome. It is interesting to speculate that cells of the secondary (and perhaps primary) myotome, as shown in Fig. 8, provide signals and cellular scaffolding as these cells elongate in the rostral caudal axis; and if these signals or cellular scaffolding are underdeveloped, migration of rib progenitors may be obstructed, and later reflected as the bifurcations and spurs (Fig. 4).

\section{Candidate signaling molecules}

A candidate signaling molecule that could mediate inductive interactions within the expanding myotome or between myotome and sclerotome was suggested by results presented here. FGF-6 is specifically expressed in myotomes starting at E9.5, about the same time that MRF4 starts to accumulate (Han and Martin, 1993; deLapeyriere et al., 1993). FGF-6 belongs to the family of fibroblast growth factors, and here we demonstrate that its levels are strongly downregulated in myotomes of MRF4 null mice ( $8 \%$ of wild type). Although the specific functions of FGF-6 are not presently known, it is an attractive candidate for intercellular signaling between cells of the myotome and the pool of proliferating precursors that are being recruited to the expanding myotome throughout its maturation. A second plausible interaction is with adjacent sclerotomal cells that are thought to include rib progenitors. Therefore, it is potentially relevant that FGF family receptors such as FGFR-1 and FGFR-2 are expressed in sclerotomal cells (Peters et al., 1992; Yamaguchi et al., 1992), but no known candidate ligands have been identified within the sclerotome itself. This raises the possibility that FGF-6 secreted from myotomes 
might act as the ligand for these receptors. The possibility of involvement of the FGF family in rib development is also suggested by recent findings of several inherited human skeletal disorders that correlate with mutations in FGF receptors, including FGFR1 and 2 (reviewed by Eriebacher et al., 1995).

The skeletal and myogenic phenotypes of MRF4 $4^{b h 1 / b h l}$ mice resemble phenotypes of mutations in two genes involved in cell-cell inductive interactions. Follistatin interacts with activin/inhibin, and modulates its function (reviewed by DePaolo et al., 1991). In follistatin null mutant mice the 13th rib is absent and, in some genetic backgrounds, the 7 th rib fails to attach to the sternum (Matzuk et al., 1995). In addition, intercostal muscles of newborn follistatin null mice showed sparse and somewhat disorganized muscle fibers, similar to MRF4 null mice. The expression pattern of follistatin is also suggestive of a role in musculoskeletal interactions. It appears in somites prior to MRF4 expression (Albano et al., 1994; Feijen et al., 1994), opening the possibility that it acts upstream of MRF4; it will be informative to study how MRF4 and $M y f-5$ are expressed in somites of follistatin null mice. BMP5 is one of the large family of bone morphogenetic factors related to TGF $\beta$. In BMP5 null mice, the 13th rib and the tuberculum anterior of the sixth cervical vertebra are absent (Kingsley et al., 1992), two features also found in $M R F 4^{b h l / b h l}$ animals. BMP5 is expressed widely in skeletal precursors (King et al., 1994), and it remains to be determined whether its expression is altered in MRF4 null mutants.

\section{Cis and trans interactions between MRF4 and Myf-5}

Myf-5 and MRF4 are located only $7 \mathrm{~kb}$ apart on the chromosome (Miner and Wold, 1990), while myogenin and MyoD are unlinked. This raises the possibility that changes at the MRF4 locus, which in this study included deletion of protein coding and first intron sequences as well as insertion of a neo selection cassette, might exert effects on $M y f-5$ in cis. A recent study by Arnold and colleagues provides evidence for such complex cis interactions (Braun and Arnold, 1995). They found that a disruption designed to remove a segment of $M R F 4$ that is entirely upstream (5') of that deleted in $M R F 4^{b h l}$ allele unexpectedly eliminated virtually all $M y f-5$ expression and function. This led to a phenocopy of the $M y f-5^{m 1 / m 1}$ rib and myotome defects. It is clear that early $M y f-5$ expression, which defines the start of the My1 program in our model, was indistinguishable from wild type in the $M R F 4^{b h 1}$ disruption (Fig. 2). Moreover, the bh1 rib defects were clearly not a phenocopy of the more extreme Myf-5 deficiency. In addition, we

Fig. 8. A summary model is proposed for myotome formation in the mouse and the role of MRF regulators in this process. It is based on the molecular and histological phenotypes of the various MRF knockouts and on the expression patterns of the MRFs according to previous in situ hybridization studies and immunohistochemical staining (reviewed by Buckingham, 1992; Smith et al., 1994). See the discussion for details and explanation. observe significant expression of $M y f-5$ at later developmental times, which further distinguishes it from the allele of Braun and Arnold (1995). We conclude that the $M R F 4^{b h 1}$ allele does not generate a wholesale cis disruption of $M y f-5$ expression. However, cis effects could be a part of the myotomal $M R F 4^{b h l / b h l}$ phenotype, if such $c$ is effects operate on a specific subset of $M y f-5$ expression that mainly overlaps spatiotemporally with $M R F 4$ expression in the wild type. Such $c i s$ effects on $M y f-5$ could also explain the RT-PCR data from E14 embryo trunks where, unlike MyoD and myogenin, Myf-5 expression remains at lower levels in $M R F 4^{b h l / b h l}$ embryos than in wild type. However, this remains only one interpretation, as at this late embryonic stage, $M y f-5$ expression in wild type is dropping relative to other MRFs and may therefore simply not play a significant part in the MyoD directed My3 program. A third MRF4 allele has been generated concurrently with these (Zhang et al., 1995). This allele removed a larger segment of protein coding sequence than in the bh1 allele, including some $3^{\prime}$ flanking sequences, and it also left a pgkneo cassette behind, though in different orientation. It displayed a rib phenotype similar in pattern formation character to $M R F 4^{b h l / b h l}$ but with a far milder effect at the point of joining to the sternum. Apparently owing to the milder rib phenotype, homozygotes of this mutation were viable, and this permitted studies of adult muscle where a five-fold relative upregulation of myogenin RNA was observed, suggesting compensation for the deficit in MRF4. It will now be interesting to compare early somitic myogenesis in the two alleles prior to E11.5. Also, given the uncertainties attached to both positive and negative regulatory influences originating from the selection cassette enhancer/promoter residue present in all three MRF4 mutations and in the $M y f-5^{m l}$ allele, analysis of this locus will benefit from new methods that allow for nearly

\section{Model for MRF Regulatory Programs in Myotome Biogenesis}

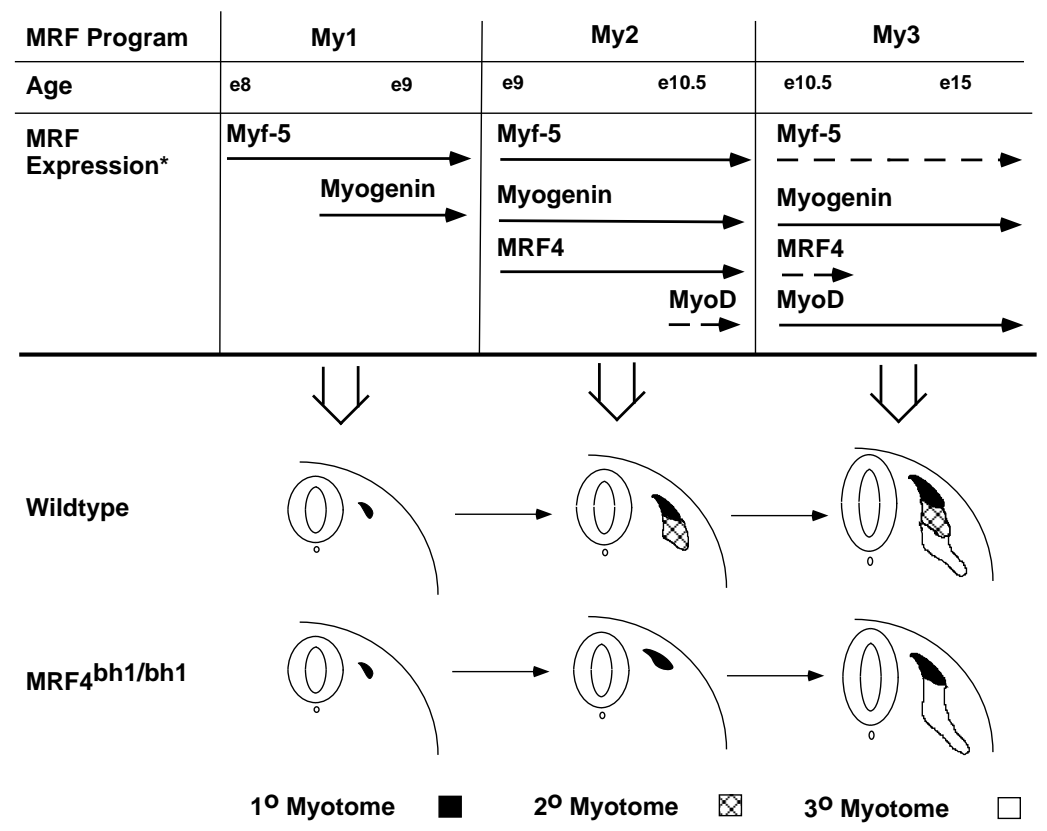

* MRF expression and myotomal domains represent forelimb level somites 
complete excision of targeting vector residue (reviewed by Sauer, 1993).

Additional questions concerning the lineage, fate and function of cells of the embryonic myotome are raised by our results. With respect to the fate of cells from the $1^{\circ}$ or $2^{\circ}$ myotome in later development, we are not aware of any cell tracing experiments that could tell us how long they live, whether they expand their domain, nor exactly where these cells might be located in the mature musculature. The cells appear to be mainly mononucleate myocytes and, by their cell number alone, they cannot make a major contribution to the mature axial musculature. The observation that rib defects occur in knockouts of any of the three MRFs that are expressed in the primary or secondary myotomes, together with the capacity of the tertiary myotome to compensate for lack of the previous two in later muscle formation, suggests that the early myotome may be mainly important as an inductive regulator and pattern formation guide for rib anlagen.

In a broader context, analysis of the $M R F 4^{b h l}$ mutant underscores the dynamic quality of the somite. We have proposed that different combinations of $M y o D$ family genes are needed to support distinct waves of cellular commitment and muscle differentiation, but why is the myotome built up in this apparently piecemeal fashion? One reason could be to limit muscle differentiation to specific subsets of precursors at early times, while others in the same signaling microenvironment are permitted to proliferate further. Also, at different times in the growth and maturation of the myotome, the sources of inductive and inhibitory interactions driving muscle determination and differentiation such as neural tube, sclerotome, earlier myotome or dermatome are themselves changing rapidly and are likely to be expressing different signals. Thus the multiplicity of MRFs may be most important, at least in the embryo, because they provide for myogenic responses to separate signaling pathways. The complexity and developmental diversity of cis regulatory elements currently being identified in MRF genes provides indirect support for this view (Patapoutian et al., 1993; Cheng et al., 1993; Yee and Rigby, 1993; Goldhammer et al. 1995), while direct tests may require gene transplacement experiments in which one MRF protein coding sequence replaces another in the mouse germline.

We thank S. Pease and L. Martin for professional assistance with ES cells and blastocyst injections. We thank Professor W. Wright for the gift of his myogenin monoclonal cell line (F5D), Professor E. Olson for communicating results prior to publication, C. Cardell for technical assistance, Caltech Imaging Facility for help with confocal microscopy, L. Lee and M. Graham for assistance in tissue culture, and Drs D. Anderson, S. Fraser, P. Garrity, N. Hong, P. Mueller, J. Sanes, and members of Wold group for helpful comments on the manuscript. A. P. was supported by an NIH Predoctoral Training Grant. This work was supported by a grant to B. W. from NIH no. AR40780 and AR42671.

\section{REFERENCES}

Albano, R. M., Arkell, R., Beddington, R. S. P. and Smith, J. C. (1994). Expression of inhibin subunits and follistatin during postimplantation mouse development: decidual expression of activin and expression of follistatin in primitive streak, somites and hindbrain. Development 120, 803-813.

Bober, E., Lyons, G. E., Braun, T., Cossu, G., Buckingham, M. and Arnold,
H.-H. (1991). The muscle regulatory gene, Myf-6, has a biphasic pattern of expression during early mouse development. J. Cell Biol. 113, 1255-1265.

Braun, T. and Arnold, H.-H. (1995). Inactivation of Myf-6 and Myf-5 genes in mice leads to alterations in skeletal muscle development. EMBO J. 14, 11761186.

Braun, T., Bober, E., Rudnicki, M. A., Jaenisch, R. and Arnold, H.-H. (1994). MyoD expression marks the onset of skeletal myogenesis in Myf-5 mutant mice. Development 120, 3083-3092.

Braun, T., Rudnicki, M. A., Arnold, H.-H. and Jaenisch. (1992). Targeted inactivation of the muscle regulatory gene $M y f-5$ results in abnormal rib development and perinatal death. Cell 71, 369-382.

Buckingham, M. (1992). Making muscle in mammals. Trends Genet. 8, 144149.

Cheng, T.-C., Wallace, M. C., Merlie, J. P. and Olson, E. N. (1993) Separable regulatory elements governing myogenin transcription in mouse embryogenesis. Science 261, 215-218.

Chomczynski, P. and Sacchi, N. (1987). Single-step method of RNA isolation by acid guanidinium thiocyanate-phenol-chloroform extraction. Anayt. Biochem. 162, 156-159.

DeLapeyriere, O., Ollendorff, V., Planche, J., Ott, M. O., Pizette, S., Coulier, F. and Birnbaum, D. (1993). Expression of the FGF6 gene is restricted to developing skeletal muscle in mouse embryo. Development 118 , 601-611.

DePaolo, L. V., Bicsak, T. A., Erickson, G. F., Shimasaki, S. and Ling, N. (1991). Follistatin and activin: A potential intrinsic regulatory system within diverse tissues. Proc. Soc. Exp. Biol. Med. 198, 500-512.

Eriebacher, A., Filvaroff, E. H., Gitelman, S. and Derynck, R. (1995). Toward a molecular understanding of skeletal development. Cell 80, 371378.

Fan, C.-M. and Tessier-Lavigne, M. (1994). Patterning of mammalian somites by surface ectoderm and notochord: evidence for sclerotome induction by a hedgehog homolog. Cell 79, 1175-1186.

Feijen, A., Goumans, M. J. and van den Eijnden-van Raaij, A. J. M. (1994). Expression of activin subunits, activin receptors and follistatin in postimplantation mouse embryos suggests specific developmental functions for different activins. Development 120, 3621-3637.

Goldhamer, D. J., Faerman, A., Shani, M. and Emerson Jr., C. P. (1992) Regulatory elements that control the lineage-specific expression of myo D. Science 256, 538-542.

Hannon, K., Smith, C. K., Bales, K. R. and Santerre, R. F. (1992). Temporal and quantitative analysis of myogenic regulatory and growth factor gene expression in the developing mouse embryo. Dev. Biol. 151, 137-144.

Han, J.-K. and Martin, G. R. (1993). Embryonic expression of FGF-6 is restricted to the skeletal muscle lineage. Dev. Biol. 158, 549-554.

Hasty, P., Bradley, A., Morris, J. H., Edmondson, D. G., Venuti, J. M., Olson, E. N. and Klein, W. H. (1993). Muscle deficiency and neonatal death in mice with a targeted mutation in the myogenin gene. Nature 364, 501506

Hinterberger, T. J., Sassoon, D. A., Rhodes, S. J. and Konieczny, S. F. (1991). Expression of the muscle regulatory factor MRF4 during somite and skeletal myofiber development. Dev. Biol. 147, 144-156.

Hopwood, N. D. and Gurdon, J. B. (1990). Activation of muscle genes without myogenesis by ectopic expression of $M y o D$ in frog embryo cells. Nature 347, 197-200.

Huang, R., Zhi, Q., Wilting, J. and Christ, B. (1994). The fate of somitocoele cells in avian embryos. Anat. Embryol. 190, 243-250.

Jan, Y. N. and Jan, L. Y. (1993). HLH proteins, fly neurogenesis, and vertebrate myogenesis. Cell 75, 827-830.

King, J. A., Marker, P. C., Seung, K. J. and Kingsley, D. M. (1994). BMP5 and the molecular, skeletal, and soft-tissue alterations in short ear mice. Dev. Biol 166, 112-122.

Kingsley, D. M., Bland, A. E., Grubber, J. M., Marker, P. C., Russell, L. B., Copeland, N. G. and Jenkins, N. A. (1992). The mouse short ear skeletal morphogenesis locus is associated with defects in a bone morphogenetic member fo the TGF $\beta$ superfamily. Cell 71, 399-410.

Lassar, A. B., Buskin, J. N., Lockshon, D., Davis, R. L., Apone, S., Hauschka, S. D. and Weintraub, H. (1989). MyoD is a sequence-specific DNA binding protein requiring a region of $m y c$ homology to bind to the muscle creatine kinase enhancer. Cell 58, 823-831.

Lassar, A. B., Davis, R. L., Wright, W. E., Kadesch, T., Murre, C., Voronova, A., Baltimore, D. and Weintraub, H. (1991). Functional activity of myogenic HLH proteins requires hetero-oligomerization with E12/E47-like proteins in vivo. Cell 66, 305-315.

Martin, J. F., Miano, J. M., Hustad, C. M., Copeland, N. G., Jenkins, N. A. 
and Olson, E. N. (1994). A Mef2 gene that generates a muscle-specific isoform via alternate mRNA splicing. Mol. Cell Biol. 14, 1647-1656.

Matzuk, M. M., Lu, N., Hannes, V., Sellheyer, K., Roop, D. R. and Bradley, A. (1995). Multiple defects and perinatal death in mice deficient in follistatin. Nature 374, 360-363.

Miner, J. H., Miller, J. B. and Wold, B. J. (1992). Skeletal muscle phenotypes initiated by ectopic MyoD in transgenic mouse heart. Development 114, 853860.

Miner, J. H. and Wold, B. (1990). Herculin, a fourth member of the MyoD family of myogenic regulatory genes. Proc. Natl. Acad. Sci. USA 87, 10891093.

Murre, C., Schonleber McCaw, P., Vaessin, H., Caudy, M., Jan, L. Y., Jan, Y. N., Cabrera, C. V., Buskin, J. N., Hauschka, S. D., Lassar, A. B., Weintraub, H. and Baltimore, D. (1989). Interactions between heterologous helix-loop-helix proteins generate complexes that bind specifically to a common DNA sequence. Cell 58, 537-544.

Nabeshima, Y., Hanaoka, K., Hayasaka, M., Esumi, E., Shaowei, L., Nonaka, I. and Nabeshima, Y.-I. (1993). Myogenin gene disruption results in perinatal lethality because of severe muscle defect. Nature 364, 532-535.

Olson, E. N. (1990). MyoD family: a paradigm for development? Genes Dev. 4, 2104-2111.

Patapoutian, A., Miner, J. H., Lyons, G. E. and Wold, B. (1993). Isolated sequences from the linked Myf-5 and MRF4 genes drive distinct patterns of muscle-specific expression in transgenic mice. Development 118, 61-69.

Peters, K. G., Werner, S., Chen, G. and Williams, L. T. (1992). Two FGF receptor genes are differentially expressed in epithelial and mesenchymal tissues during limb formation and organogenesis in the mouse. Development 114, 233-243.

Robinson, M. O. and Simon, M. I. (1991). Determining transcript number using the polymerase chain reaction: PGK-2, $\mathrm{mP} 2$ and PGK-2 trangene mRNA levels during spermatogenesis. Nucl. Acid Res. 19, 1557-1562.

Rudnicki, M. A., Braun, T., Hinuma, S. and Jaenisch. (1992). Inactivation of $M y o D$ in mice leads to upregulation of the myogenic HLH gene $M y f-5$ and results in apparently normal muscle development. Cell 71, 383-390.

Rudnicki, M. A., Schneglesberg, P. N. J., Stead, R. H., Braun, T., Arnold, H.-H. and Jaenisch, R. (1993). MyoD or Myf-5 is required for the formation of skeletal muscle. Cell 75, 1351-1359.

Rugh, R. (1968). The Mouse: Its Reproduction and Development. Minneapolis: Burgess Publishing Company

Sambrook, J., Fritsch,E. R. and Maniatis, T. 1989. Molecular Cloning: A Laboratory Manual., 2nd ed. Cold Spring Harbor, New York: Cold Spring Harbor Laboratory Press.

Sassoon, D., Lyons, G., Wright, W. E., Lin, V., Lassar, A., Weintraub, H. and Buckingham, M. (1989). Expression of two myogenic regulatory factors myogenin and MyoDl during mouse embryogenesis. Nature (London) 341, 303-307.

Sauer, B. (1993). Manipulation of transgenes by site-specific recombination use of cre. Methods in Enzymol. 225, 890-900.
Smith, T. H., Kachinsky, A. M. and Miller, J. B. (1994). Somite subdomains, muscle cell origins, and the four muscle regulatory proteins. J. Cell Biol. 127, 95-105.

Tapscott, S. J., Davis, R. L., Thayer, M. J., Cheng, P.-F., Weintraub, H. and Lassar, A. B. (1988). MyoD1: a nuclear phosphoprotein requiring a myc homology region to convert fibroblasts to myoblasts. Science $\mathbf{2 4 2}$, 405-411.

Wachtler, F. and Christ, B. (1992). The basic embryology of skeletal muscle formation in vertebrates: the avian model. Sem. Dev. Biol. 3, 217-227.

Walterhouse, D., Ahmed, M., Slusarski, D., Kalamaras, J., Boucher, D. Holmgren, R. and Iannaccone, P. (1993). gli, a zinc finger transcription factore and oncogene, is expressed during normal mouse development. Dev. Dynam. 196, 91-102.

Weintraub, H. (1993). The MyoD family and myogenesis - networks, and thresholds. Cell 75, 1241-1244.

Weintraub, H., Davis, R., Tapscott, S., Thayer, M., Krause, M., Benezra, R., Blackwell, T. K., Turner, D., Rupp, R., Hollenberg, S., Zhuang, Y. and Lassar, A. (1991). The myoD gene family: nodal point during specification of the muscle cell lineage. Science 251, 761-766.

Yamaguchi, T. P., Conlon, R. A. and Rossant, J. (1992). Expression of the fibroblast growth factor receptor FGFR-1.flg during gastrulation and segmentation in the mouse embryo. Dev. Biol. 152, 75-88.

Yee, S.-P. and Rigby, P. W. J. (1993). The regulation of myogenin gene expressed during the embryonic development of the mouse. Genes. Dev. 7, 1277-1289.

Yutzey, K. E., Rhodes, S. J. and Konieczny, S. F. (1990). Differential trans activation associated with the muscle regulatory factors MyoD1, myogenin and MRF4. Mol. Cell. Biol. 10, 3934-3944.

Zhang, W., Behringer, R. R. and Olson, E. N. (1995). Inactivation of the myogenic bHLH gene MRF4 results in upregulation of myogenin and rib anomalies. Genes Dev. 9, 1388-1399.

(Accepted 23 June 1995)

\section{Notes added in proof}

(1) The MRF4 ${ }^{\text {bh } 1}$ mouse line has been accepted by the Jackson Laboratory Genetic Resource Committee, and it will be distributed through the Jackson Laboratory. (2) We have recently observed one apparently healthy homozygous MRF5 ${ }^{\text {bh } 1 / b h 1}$ adult animal. Ongoing studies are needed to clarify whether this represents a low penetrance event or instead reflects a change in genetic background that is part of the breeding program. 